\section{Motociclistas de entrega: algumas características dos acidentes de trânsito na Região Sul do Brasil}

\section{Motorcycle couriers: characteristics of traffic accidents in southern Brazil}

Resumo

Objetivo: conhecer características dos acidentes de trânsito ocorridos com motoboys nos municípios de Londrina e Maringá, Estado do Paraná. Métodos: Foram considerados 327 motoboys que relataram, em 2005/2006, acidentes de motocicleta nos 12 meses anteriores à pesquisa (147 de Londrina e 180 de Maringá). Resultados: Dos entrevistados, $39,6 \%$ relataram mais de um acidente de trânsito. Os acidentes foram percebidos como graves por $21,4 \%$ dos motoboys e 56,3\% relataram conhecer motoboy afastado do trabalho por acidente. A maioria dos acidentes (82,9\%) ocorreu durante o trabalho. Foram observadas diferenças significativas, entre os municípios, para condições climáticas ( $\mathrm{p}=0,013)$, período do dia $(\mathrm{p}=0,002)$, atendimento pré-hospitalar $(\mathrm{p}=0,032)$ e necessidade de internação hospitalar $(p<0,001)$. Conclusão: $A$ alta incidência e reincidência de acidentes de trânsito reforçam a susceptibilidade dos motoboys a esses eventos e a necessidade de estratégias e políticas específicas de prevenção.

Palavras-chave: motocicletas; acidentes de trânsito; acidentes de trabalho; consequências de acidentes; prevenção de acidentes; epidemiologia.

\section{Dorotéia Fátima Pelissari de Paula Soares' \\ Thais Aidar de Freitas Mathias" \\ Daniela Wosiack da Silva"I \\ Selma Maffei de Andrade ${ }^{\text {IV }}$ \\ 'Departamento de Enfermagem da Universidade Estadual de Maringá - Maringá (PR), Brasil \\ "Programa de Pós-Graduação em Enfermagem do Departamento de Enfermagem da Universidade Estadual de Maringá - Maringá (PR), Brasil "'Departamento de Fisioterapia da Universidade Estadual de Londrina - Londrina (PR), Brasil \\ IvPrograma de Pós-Graduação em Saúde Coletiva da Universidade Estadual de Londrina - Londrina (PR), Brasil}

Trabalho realizado na Universidade Estadual de Londrina e na Universidade Estadual de Maringá - Maringá (PR), Brasil.

Fonte de financiamento: Departamento de Ciência e Tecnologia da Secretaria de Ciência,

Tecnologia e Insumos Estratégicos do Ministério da Saúde e Conselho Nacional de

Desenvolvimento Científico e Tecnológico (CNPq), edital CT-Saúde/CNPq 24/2004 - processo n 505.875/2004-7.

Correspondência: Dorotéia Fátima Pelissari de Paula Soares - Av. Colombo, 5.790 - Jardim Universitário - CEP: 87020-900 - Maringá (PR), Brasil - E-mail: doroteiasoares@uol.com.br Conflito de interesse: nada a declarar. 


\section{Abstract}

Objective: This study aimed at understanding characteristics of traffic accidents with motorcycle couriers in the cities of Londrina and Maringá, in the State of Paraná (Brazil). Methods: A total of 327 couriers who reported, in 2005/2006, motorcycle accident in the previous 12 months took part in the study (147 in Londrina and 180 in Maringá). Results: Of all the interviewed, 39.6\% reported more than one traffic accident. The accidents were perceived as serious by $21.4 \%$ of them and $56.3 \%$ reported knowing a convalescing courier due to a traffic accident. Most injuries (82.9\%) occurred during work hours. Significant differences were observed between the cities concerning climatic conditions ( $\mathrm{p}=0.013$ ), time of the day $(\mathrm{p}=0.002)$, pre-hospital care $(\mathrm{p}=0.032)$ and hospital admission $(\mathrm{p}<0.001)$. Conclusion: The high incidence and the recurrence of traffic accidents highlight the susceptibility of motorcycle couriers to these events and the need for strategies and specific prevention policies.

Keywords: motorcycles; accidents, traffic; accidents, occupational; consequences, accident; accident prevention; epidemiology.

\section{Introdução}

Estudos têm mostrado que os acidentes de transporte envolvendo motociclistas são causas importantes de morbidade e mortalidade no Brasil ${ }^{1-6}$, assim como em outros países $^{7,8}$. Observa-se tendência crescente de uso da motocicleta no Brasil devido à facilidade de compra, por acesso ao crédito e ampliação dos prazos de pagamento, que atraem um número cada vez maior de consumidores. Entre 2002 e 2008, a frota de motocicletas aumentou em 137,8\%, e o ano de 2008 terminou com 11 milhões de motocicletas registradas em todo o país pelo Departamento Nacional de Trânsito (Denatran). Este aumento representa 3,2 vezes o de veículos de passeio para o mesmo período ${ }^{9}$. Como uma das consequências, observa-se aumento dos acidentes de motocicleta. Dados do Ministério da Saúde mostram aumento de $190,5 \%$ no número de mortes por acidentes de transporte entre motociclistas de 2000 a 2006, superior ao aumento proporcional das mortes de ciclistas $(111,4 \%)$, pedestres $(16,7 \%)$ e condutores de veículo de passeio $(45,1 \%)^{10}$.

Além de meio de transporte de baixo custo, a motocicleta serve também como instrumento de trabalho, para transporte de pessoas (moto-táxi) ou de mercadorias (moto-frete ou moto-entrega). O aumento na quantidade de motociclistas que fazem fretes (motoboys ou motociclistas de entrega) é visível nos centros urbanos do país, visto que esses trabalhadores atendem às necessidades de rapidez e agilidade na prestação de serviços e entrega de produtos, e sua presença e tendência de crescimento parecem irreversíveis a curto e médio prazo ${ }^{11}$.

Neste contexto, de agilidade, necessidade de rapidez, sociedade de consumo e trânsito caótico, os motoboys representam uma população de grande risco de envolvimento em acidentes de trânsito. Precárias condições de trabalho e alta exposição a situações de risco contribuem para a elevada taxa de acidentes de trânsito entre motoboys $^{12}$. Entretanto, no Brasil, existem 
poucos estudos a respeito do perfil desses motociclistas de entrega e das características dos acidentes ocorridos com essa categoria de trabalhadores. Considerando que os motoboys representam parte importante dos condutores no trânsito brasileiro e que são mais expostos a acidentes, pretendeu-se, com este estudo, conhecer as características dos acidentes de trânsito ocorridos com motoboys atuantes em dois municípios do Estado do Paraná, Região Sul do Brasil.

\section{Métodos}

Estudo de delineamento transversal realizado nos municípios de Londrina e Maringá, localizados no Norte do Paraná, com populações projetadas de aproximadamente 510 mil e 335 mil habitantes, respectivamente ${ }^{13}$.

Este estudo é parte de pesquisa mais abrangente que descreve o perfil do trabalho de motociclistas de entrega nesses municípios, quando foram pesquisados 877 motoboys. Para a definição da amostra em Londrina e em Maringá foi necessário identificar, durante um período de três meses anteriores à pesquisa, os principais tipos de empresa que utilizavam os serviços de entrega, o que foi feito por meio de observação nas principais vias públicas dos dois municípios. Posteriormente, por contatos telefônicos às empresas identificadas, foi levantado o número de motoboys atuantes em cada cidade. Devido à capacidade das equipes de pesquisa em cada município, em Londrina foi selecionada uma amostra de $50 \%$ do universo, de forma aleatória sistemática, de maneira a garantir proporcionalidade do número de motoboys atuantes em cada tipo de empresa e a representatividade do universo. Da amostra selecionada, foram entrevistados 377 motoboys, correspondendo a 95,9\% dos selecionados. Em Maringá, considerando as perdas, foram entrevistados $98,8 \%$ do total, ou seja, 500 motoboys. Destes, foram considerados, no presente estudo, 327 motoboys que relataram acidentes de motocicleta nos
12 meses anteriores à entrevista, sendo 147 de Londrina e 180 de Maringá. Os motoboys foram abordados em seus locais de trabalho por pesquisadores de campo devidamente treinados, de setembro a novembro de 2005 em Londrina, e de junho a dezembro de 2006 em Maringá, e responderam a um questionário anônimo e auto-aplicável. A descrição detalhada do procedimento de seleção da população e amostra de estudo e da construção e aprimoramento do instrumento de coleta dos dados estão relatados em estudo anterior ${ }^{12}$.

Os motoboys foram questionados quanto ao número de acidentes nos últimos 12 meses (1, 2, 3, 4 e mais acidentes). Para os dois últimos acidentes ocorridos, perguntou-se se considerou o acidente grave ( $\mathrm{sim}$ ou não); se no momento do acidente estava trabalhando ou não; qual foi o tipo de acidente (queda da moto, colisão com outro veículo - carro, moto, bicicleta ou outro, colisão com pedestre/animal ou colisão com objeto fixo/anteparo); quais eram as condições climáticas do momento do acidente (tempo seco ou chuvoso); qual o dia da semana em que ocorreu o acidente (dias úteis ou finais de semana); em qual período do dia (dia ou noite); se houve atendimento pré-hospitalar pelo Serviço Integrado de Atendimento ao Trauma e às Emergências (SIATE) (sim ou não), atendimento hospitalar ( sim ou não) e internação hospitalar (sim ou não). Para melhor mensurar a dimensão do problema dos acidentes de trânsito, foi também questionado ao motoboy se ele conhecia algum colega que estivesse afastado do trabalho devido a acidente de moto, sendo admitidas as categorias: sim ou não. Os atendimentos recebidos, tanto do SIATE como hospitalar, são referentes apenas aos motoboys e não aos possíveis outros feridos envolvidos no acidente.

Os dados foram tabulados pelo programa Epi Info $6.04 \mathrm{~d}^{14}$ e analisados após dupla digitação, comparação e correção. Foi utilizado o teste do $\chi^{2}$ sem correção de continuidade, com nível de significância de 0,05 , para comparação das características dos acidentes nos dois municípios. 
Os participantes do estudo responderam ao questionário após a leitura do termo de consentimento livre e esclarecido e de manifestarem sua concordância em participar do estudo. O projeto de pesquisa foi aprovado pelo Comitê de Ética em Pesquisa da Universidade Estadual de Londrina (Parecer CEP 287/04).

\section{Resultados}

Do total de motoboys entrevistados (877), observou-se predomínio absoluto do sexo masculino (99,7\% em Londrina e 99,6\% em Maringá). Em Londrina, a maior parte dos motoboys tinha entre 18 e 24 anos (43\%) e, em Maringá, entre 25 e 34 anos $(41,6 \%)$. Do total, $37,3 \%$ relataram acidente nos 12 meses anteriores à entrevista (39,0\% em Londrina e 36,0\% em Maringá, sem diferença estatisticamente significativa). Entre os que relataram acidentes, $99,4 \%$ eram do sexo masculino (99,3\% e 99,4\% em Londrina e em Maringá, respectivamente) e 47,4\% tinham idade entre 18 e 24 anos (44,4\% em Londrina e 55,6\% em Maringá).

A Tabela 1 mostra que não houve diferenças significativas, entre os dois municípios, para o número de acidentes sofridos, a gravidade percebida do acidente, o tipo de atividade no momento do acidente e o conhecimento de algum outro motoboy afastado do trabalho por acidente. Dos 327 motoboys acidentados, $39,6 \%$ relataram mais de um acidente de trânsito nos 12 meses anteriores à entrevista. A ocorrência de dois ou mais acidentes foi maior entre os motoboys de Londrina (42,3\%, em comparação a 36,8\% em Maringá). O acidente foi relatado como grave por $21,4 \%$ dos entrevistados, com maior frequência em Londrina (23,8\%) do que em Maringá $(19,3 \%)$. A maior parte dos acidentes $(82,9 \%)$ ocorreu durante o trabalho, e mais da metade dos motoboys $(56,3 \%)$ relatou conhecer colegas afastados do trabalho

Tabela 1. Número e características dos acidentes e relato de conhecimento de motoboy afastado devido a acidentes. Londrina e Maringá, 2005 e 2006

Table 1. Number, characteristics of accidents and report of knowledge of a motorcycle courier who was on leave due to an accident. Londrina and Maringá, 2005 and 2006

\begin{tabular}{|c|c|c|c|c|c|c|c|}
\hline \multirow[t]{2}{*}{ Variáveis } & \multicolumn{2}{|c|}{$\begin{array}{l}\text { Londrina } \\
(n=147)\end{array}$} & \multicolumn{2}{|c|}{$\begin{array}{l}\text { Maringá } \\
(\mathrm{n}=180)\end{array}$} & \multicolumn{2}{|c|}{$\begin{array}{c}\text { Total } \\
(\mathrm{n}=327)\end{array}$} & \multirow[t]{2}{*}{$p$} \\
\hline & $\mathrm{n}$ & $\%$ & $\mathrm{n}$ & $\%$ & $\mathrm{n}$ & $\%$ & \\
\hline \multicolumn{8}{|c|}{ Número de acidentes* } \\
\hline 1 & 84 & 57,1 & 113 & 63,2 & 197 & 60,4 & \multirow[t]{4}{*}{$0,559^{\#}$} \\
\hline 2 & 32 & 21,8 & 37 & 20,6 & 69 & 21,2 & \\
\hline 3 & 15 & 10,2 & 12 & 6,7 & 27 & 8,3 & \\
\hline 4 ou mais & 16 & 10,9 & 17 & 9,5 & 33 & 10,1 & \\
\hline \multicolumn{8}{|c|}{ Gravidade do acidente** } \\
\hline Sim & 35 & 23,8 & 34 & 19,3 & 69 & 21,4 & \multirow[t]{2}{*}{0,327} \\
\hline Não & 112 & 76,2 & 142 & 80,7 & 254 & 78,6 & \\
\hline \multicolumn{8}{|c|}{ Atividade no momento do acidente } \\
\hline Trabalho & 121 & 82,3 & 150 & 83,3 & 271 & 82,9 & \multirow[t]{2}{*}{0,808} \\
\hline Lazer & 26 & 17,7 & 30 & 16,7 & 56 & 17,1 & \\
\hline \multicolumn{8}{|c|}{ Conhece motoboy afastado } \\
\hline Sim & 91 & 61,9 & 93 & 51,7 & 184 & 56,3 & \multirow[t]{2}{*}{0,063} \\
\hline Não & 56 & 38,1 & 87 & 48,3 & 143 & 43,7 & \\
\hline
\end{tabular}

Percentual calculado excluindo as respostas ignoradas; ${ }^{*}$ Questão respondida por 179 motoboys em Maringá; ** Questão respondida por 176 motoboys em Maringá; "Graus de liberdade=3 
por acidentes de moto $(61,9 \%$ em Londrina e 51,7\% em Maringá).

Na Tabela 2 estão apresentadas as características do último e do penúltimo acidentes ocorridos nos 12 meses anteriores à pesquisa. Para esta análise, foram somadas as características do último e penúltimo acidente, totalizando 371 nos dois municípios, sendo 178 em Londrina e 193, em Maringá. Entre os acidentes, predominaram as colisões com carro, moto, bicicleta ou outro veículo $(62,4 \%)$, mais frequentes para os motoboys de Londrina do que de Maringá (65,6\% e 59,5\%, respectivamente). Além das colisões, as quedas de moto foram responsáveis por $27,5 \%$ dos acidentes, mais frequentes para os motoboys de Maringá - 32,6 contra $22,0 \%$ em Londrina.

Houve predomínio de acidentes em dias secos e durante o dia, significativamente mais frequentes em Maringá $(\mathrm{p}=0,013 \mathrm{e}$ $\mathrm{p}=0,002$ respectivamente). A maioria dos

Tabela 2 . Características do último e/ou penúltimo acidente ocorrido nos doze meses anteriores à entrevista. Londrina e Maringá, 2005 e 2006

Table 2. Characteristics of the last and/or the penultimate accident that occurred in the last 12 months before the interview. Londrina and Maringá, 2005 and 2006

\begin{tabular}{|c|c|c|c|c|c|c|c|}
\hline \multirow[t]{2}{*}{ Variáveis } & \multicolumn{2}{|c|}{$\begin{array}{l}\text { Londrina } \\
(\mathrm{n}=178)\end{array}$} & \multicolumn{2}{|c|}{$\begin{array}{l}\text { Maringá } \\
(n=193)\end{array}$} & \multicolumn{2}{|c|}{$\begin{array}{c}\text { Total } \\
(\mathrm{n}=371)\end{array}$} & \multirow[t]{2}{*}{$\mathrm{p}$} \\
\hline & $\mathrm{n}$ & $\%$ & $\mathrm{n}$ & $\%$ & $\mathrm{n}$ & $\%$ & \\
\hline \multicolumn{8}{|l|}{ Tipo de acidente* } \\
\hline $\begin{array}{l}\text { Colisão (com carro, moto, bicicleta ou outro) } \\
\text { veículo carro/moto/bicicleta/outro veículo }\end{array}$ & 116 & 65,6 & 113 & 59,5 & 229 & 62,4 & $0,093^{\#}$ \\
\hline Queda de moto & 39 & 22,0 & 62 & 32,6 & 101 & 27,5 & \\
\hline Colisão com pedestre/animal & 16 & 9,0 & 12 & 6,3 & 28 & 7,6 & \\
\hline Colisão com objeto fixo/anteparo & 06 & 3,4 & 03 & 1,6 & 9 & 2,5 & \\
\hline \multicolumn{8}{|l|}{ Condições climáticas } \\
\hline Dia seco & 134 & 75,3 & 165 & 85,5 & 299 & 80,6 & 0,013 \\
\hline Dia chuvoso & 44 & 24,7 & 28 & 14,5 & 72 & 19,4 & \\
\hline \multicolumn{8}{|l|}{ Dia da semana** } \\
\hline Dias úteis & 138 & 77,5 & 164 & 85,0 & 302 & 81,4 & 0,062 \\
\hline Finais de semana/feriados & 38 & 21,3 & 27 & 14,0 & 65 & 17,5 & \\
\hline \multicolumn{8}{|l|}{ Período do dia*** } \\
\hline Dia & 116 & 65,2 & 152 & 79,6 & 268 & 72,8 & 0,002 \\
\hline Noite & 62 & 34,8 & 39 & 20,4 & 101 & 27,2 & \\
\hline \multicolumn{8}{|l|}{ Atendimento pré-hospitalar (SIATE) } \\
\hline Sim & 53 & 29,8 & 78 & 40,4 & 131 & 35,3 & 0,032 \\
\hline Não & 125 & 70,2 & 115 & 59,6 & 240 & 64,7 & \\
\hline \multicolumn{8}{|l|}{ Atendimento hospitalar } \\
\hline Sim & 64 & 37,6 & 69 & 37,7 & 133 & 37,7 & 0,991 \\
\hline Não & 106 & 63,4 & 114 & 62,3 & 220 & 62,3 & \\
\hline \multicolumn{8}{|l|}{ Internação hospitalar**** } \\
\hline Sim & 22 & 12,4 & 46 & 26,3 & 68 & 19,3 & $<0,001$ \\
\hline Não & 156 & 87,6 & 129 & 73,7 & 285 & 80,7 & \\
\hline
\end{tabular}

Percentual calculado excluindo-se as respostas ignoradas; "Questão respondida por 190 motoboys em Londrina e 177 motoboys em Maringá; " Questão respondida por 176 motoboys em Londrina e 191 motoboys em Maringá; " "*" Questão respondida por 191 motoboys em Maringá; " "**" Questão respondida por 175 motoboys em Maringá; "Graus de liberdade=3 
acidentes ocorreu em dias úteis $(81,4 \%)$, sem diferenças significativas entre as duas cidades. $\mathrm{O}$ atendimento pré-hospitalar pelo SIATE $(\mathrm{p}=0,032)$ e a internação hospitalar $(\mathrm{p}<0,001)$ foram também mais frequentes para os motoboys do município de Maringá.

\section{Discussão}

Este estudo mostra o quanto foram frequentes os acidentes de trânsito entre os motoboys, pois quase $40 \%$ referiram pelo menos um acidente nos últimos 12 meses. A reincidência de acidente de trânsito é uma característica presente nessa classe de trabalhadores, visto que $39,6 \%$ dos que relataram acidentes referiram envolvimento em 2 ou mais acidentes (42,9\% em Londrina e $36,8 \%$ em Maringá). Esses achados concordam com os encontrados em algumas cidades do Brasil ${ }^{15,16}$ e de outros países ${ }^{8,17}$, onde foram observadas frequências importantes de relatos de envolvimento em mais de um acidente. Vale lembrar que o número de episódios de acidentes relatados por esses trabalhadores poderia ser maior, considerando que, na categoria de quatro ou mais acidentes, a referência para o cálculo foi de quatro acidentes, pois não se dispunha do número real acima dessa quantidade de acidentes.

É importante destacar que os resultados deste estudo mostram características dos motoboys que estavam em atividade; portanto, mostram parte da magnitude de acidentes. Existe uma quantidade desconhecida de motoboys afastados do trabalho devido a essas ocorrências, provavelmente graves, e que não foram entrevistados. De acordo com os relatos, $61,9 \%$ dos motoboys de Londrina e 51,7\% dos de Maringá afirmaram conhecer algum colega atualmente afastado do trabalho devido a acidente de trânsito. Isso mostra que, excluída a possibilidade de duplicação dos motoboys acidentados, ou seja, mais de um entrevistado se referindo ao mesmo motoboy, seria observado um grande incremento no número de acidentados no último ano, caso fossem considerados, no presente estudo, os afastados do trabalho em decorrência de acidentes. No município de Vitória, o conhecimento de algum colega envolvido gravemente em algum acidente foi referido por $89,9 \%$ dos motoboys, valor indicativo de que o fenômeno do acidente é uma constante que paira sobre o cotidiano desses trabalhadores ${ }^{18}$.

O elevado percentual de motoboys que relatou ocorrência de acidentes no momento de trabalho $(82,9 \%)$ reflete a susceptibilidade desses trabalhadores a esses eventos, certamente por aspectos inerentes à sua profissão, como as precárias condições de trabalho e alta exposição a situações de risco no trânsito ${ }^{12}$. A vulnerabilidade dos motoboys à ocorrência de acidentes de trânsito também foi observada em estudos realizados em Porto Alegre (RS) ${ }^{19}$, Campinas $(\mathrm{SP})^{20}$ e Vitória (ES) ${ }^{18}$. Os autores consideram o estresse causado pelas más condições de trabalho como um fator que contribui para a ocorrência de acidentes de trânsito. Os motoboys são vítimas desse estresse, pois, em seu exercício profissional, arriscam-se no trânsito para serem rápidos na entrega de mercadorias.

Entre motociclistas atendidos em um pronto-socorro de Porto Alegre (RS) e que relataram ter sofrido acidentes anteriores, foi observada associação significativa com a profissão que exerciam de motoboy ${ }^{21}$. Foi verificado que entre os pacientes com história pregressa de acidente e que exerciam a profissão de motoboy existia uma quantidade de casos de acidentes significativamente maior em comparação aos motociclistas que trabalhavam em outras áreas, como também uma relação significativa com o tempo rodado por dia.

O fato de $21,4 \%$ dos motoboys deste estudo terem considerado o acidente como grave sugere que o nível de gravidade desses eventos não foi suficiente para incapacitá-los e que houve afastamento apenas temporário das atividades, porquanto estavam trabalhando no momento da entrevista. Outra questão que se coloca é o critério de gravidade, que não foi estabelecido 
no questionário, ficando a critério do entrevistado essa classificação. Supõe-se que alguns aspectos podem ter levado os motoboys a considerarem o acidente como grave, destacando-se a necessidade de socorro pré-hospitalar, necessidade de internação, o tempo de internação e o possível afastamento do trabalho.

Esses acidentes, principalmente os de maior gravidade, certamente resultam em grande impacto no cotidiano desses trabalhadores, comprometendo principalmente o retorno à atividade produtiva. Um dos poucos estudos que aborda este aspecto mostra que entre motoboys do município de Vitória que relataram envolvimento em acidente de trânsito, $65 \%$ ficaram afastados do trabalho em função do acidente e, destes, quase $35 \%$ ficaram afastados por mais de 30 dias. Além disso, cerca de um terço dos profissionais que ficaram afastados relatou não ter tido acesso a qualquer tipo de benefício social, seja da empresa, seja do Instituto Nacional de Previdência Social (INSS) ${ }^{18}$.

Embora as diferenças com relação ao número de acidentes de trânsito, gravidade do acidente e conhecimento de motoboy afastado do trabalho não tenham sido significativas entre Maringá e Londrina, as maiores frequências dessas características observadas em Londrina podem, talvez, ser explicadas pelas piores condições de trabalho relatadas pelos motoboys desse município, além de sua maior exposição a fatores de risco, situações constatadas em estudo que analisou as condições de trabalho dessa mesma população ${ }^{12}$.

Os tipos de acidentes mais frequentes foram a colisão com outro veículo (carro, moto, bicicleta ou outro) e queda de moto, dados concordantes com os de outros estudos realizados nos mesmos municípios ${ }^{22,23}$. Estudo realizado com motociclistas da Índia ${ }^{24}$ mostra que a colisão com outro veículo também é mais frequente; no entanto, naquele país, a colisão com objeto fixo é o segundo principal tipo. Há que se destacar que o presente trabalho não objetivou identificar especificamente o tipo do outro veículo envolvido na colisão, e que antes do preenchimento dos questionários os motoboys foram orientados a considerar as quedas como acidentes de trânsito, na tentativa de se evitar o sub-relato de acidentes, visto que para muitos motoboys esse tipo de ocorrência não é considerado acidente de trânsito ${ }^{25}$. Independentemente do tipo de acidente, pode-se dizer que usuários de moto sempre estarão em desvantagem em relação aos usuários de outros veículos a motor, uma vez que o corpo do motociclista está totalmente exposto, diferentemente do condutor do carro, que tem a lataria como proteção, tornando assim o usuário de moto mais vulnerável a traumas múltiplos de maior gravidade ${ }^{26}$.

O predomínio de ocorrência de acidentes em dias úteis e durante o dia, relatado pelos motoboys, é coerente com as características de trabalho dessa categoria profissional, uma vez que estão mais expostos em ruas e avenidas nos horários em que o comércio está em plena atividade, diferentemente dos motociclistas em geral, que se acidentam mais nos finais de semana e durante a noite ${ }^{3,5,24,27}$. Resultados de estudo com motoboys de Porto Alegre ${ }^{27}$ concordam com os desta pesquisa, com maior frequência de acidentes no período do dia. A autora aponta como possível explicação o fato de fazer parte da dinâmica de trabalho desses profissionais o maior número de entregas no final do expediente das empresas, visando à conclusão de suas tarefas antes de começarem a trabalhar no período noturno em outros estabelecimentos comerciais.

Neste estudo, as diferenças entre os acidentes nos dois municípios mostraram-se significativas para condições climáticas $(\mathrm{p}=0,013)$ e período do dia $(\mathrm{p}=0,002) . \mathrm{Em}$ Londrina, os acidentes aconteceram em maior proporção em dias chuvosos, durante a noite e em finais de semana, quando comparados com os ocorridos em Maringá. Alguns aspectos precisam ser investigados para entender melhor as diferenças que se apresentam. O porte da cidade de Londrina, com população superior a 500 mil habitantes e aproximadamente $50 \%$ maior que a de Maringá, possivelmente leve a população 
a adotar hábitos de grandes centros urbanos, como a maior utilização de serviços de entrega rápida, como refeições prontas, principalmente à noite e nos finais de semana. A exemplo disso, estudo ${ }^{12}$ realizado com essa mesma população mostra que existem diferenças importantes no perfil de trabalho dos motoboys atuantes nessas duas cidades quanto ao tipo de empresa empregadora, condições de trabalho e comportamento de risco. Quanto ao tipo de empresa, existe predominância de motoboys empregados em restaurantes, lanchonetes e pizzarias em Londrina, indicando, possivelmente, hábitos mais frequentes da população em adquirir refeições prontas, gerando, consequentemente, maior proporção desses profissionais com trabalho no período noturno, jornadas diárias de trabalho superiores a 10 horas e sensação de cansaço durante o trabalho.

Chamou a atenção, no presente trabalho, o baixo percentual de motoboys que relataram ter sido atendidos pelo serviço pré-hospitalar (SIATE) nos dois municípios $(35,3 \%)$, inferior ao percentual observado de $53,2 \%$ de atendimento pré-hospitalar entre ocupantes de motocicleta em Belo Horizonte $(\mathrm{MG})^{28}$. É importante destacar que este serviço contribui significativamente para a redução do número de óbitos e da gravidade com que os casos chegam ao atendimento hospitalar, além de reduzir o tempo de transporte até o hospital ${ }^{28}$, devendo, portanto, ser assegurado a todas as vítimas de acidentes de trânsito ${ }^{3}$.

A necessidade de atendimento hospitalar referida pelos motoboys mostrou valores aproximados nos dois municípios, ao contrário da internação hospitalar que foi maior em Maringá $(26,3 \%)$ do que em Londrina $(12,4 \%)(p<0,001)$. O risco de internação de vítimas de acidentes constitui um indicador de gravidade, podendo ser utilizado para monitorar tendências, além de quantificar um evento que representa um custo importante na demanda aos serviços de saúde ${ }^{26}$.

Estudos realizados em ambos os municípios que analisaram taxas de internação de motociclistas revelam taxas maiores em Maringá (aproximadamente $40 \%)^{4,26}$, quase 4 vezes a de Londrina $(11,7 \%)^{1}$. Os diferentes achados se devem, provavelmente, às diferenças metodológicas entre os estudos, pois, neste, os resultados foram baseados em relato de motoboys, ao passo que nas pesquisas realizadas em Maringá ${ }^{4,26}$ foram estudadas as vítimas registradas pela polícia de trânsito e atendidas pelo SIATE (possivelmente casos mais graves), e em Londrina ${ }^{1}$, foram analisadas as vítimas registradas pela polícia, as que receberam atendimento de urgência/ emergência ou que morreram. Destaca-se, no entanto, que a taxa de relato de internação entre motoboys de Londrina (12,4\%) foi semelhante à observada em estudo anterior ${ }^{1}$ que buscou abranger a totalidade das vítimas de acidentes de trânsito $(11,7 \%)$.

Os resultados deste trabalho mostram a alta incidência de acidentes de trânsito durante o exercício profissional dos motoboys, bem como a reincidência de acidentes, que reforçam a susceptibilidade a esses eventos e a necessidade de estratégias e políticas específicas de prevenção, uma vez que o fenômeno do acidente de trânsito com motoboys não está relacionado apenas ao seu comportamento, mas também com o meio e com as regras do mercado, estabelecidas por patrões e clientes ${ }^{6,20,25,29}$.

Cabe destacar que o presente estudo foi desenvolvido já há alguns anos (em 2005/2006) e que os resultados apresentados se referem a uma realidade específica daquele momento, servindo de base para avaliações posteriores frente a possíveis ações de prevenção. No entanto, acredita-se que a situação pouco ou nada tenha se alterado após esse período, pois não houve intervenções mais amplas, até recentemente, que alterassem esse quadro. Somente em julho de 2009, foi sancionada a Lei $\mathrm{n}^{\circ} 12.009^{30}$, regulamentando o exercício das atividades dos moto-taxistas e motoboys e dispondo sobre a necessidade de idade mínima de 21 anos, posse de habilitação na categoria motocicletas por pelo menos 2 anos, aprovação em curso especializado e 
uso de colete de segurança dotado de dispositivos retrorrefletivos para esses trabalhadores. Recentemente, em agosto de 2010, o Conselho Nacional de Trânsito (CONTRAN) regulamentou os requisitos mínimos de segurança para o transporte remunerado de passageiros e de cargas em motocicletas e motonetas, incluindo a obrigatoriedade de equipamentos de proteção (protetor de pernas e motor e aparador de linha corta-pipa) e limites máximos de carga e de dimensão de caixas de transporte, com prazo até agosto de 2011 para adequações ${ }^{31}$. A aplicação rigorosa das normas contidas nessa Lei e na Resolução do CONTRAN é ainda uma incógnita na maioria das cidades brasileiras.

A falta de fiscalização com relação ao cumprimento da legislação de trânsito é fator importante a se considerar como estratégia para a redução dos acidentes, pois, a partir da implantação do Código Brasileiro de Trânsito em 1998, que envolveu algumas medidas como ampla divulgação da lei e fiscalização, estudos mostram que houve impacto na redução das mortes por acidentes de trânsito, que não se manteve nos anos subsequentes, justamente por falta de continuidade dessas ações ${ }^{32}$.

Importante ressaltar aqui que pouco se sabe sobre as consequências dos acidentes no cotidiano dos motoboys, pois deste estudo participaram os que relataram acidentes de trânsito, mas que já estavam trabalhando, não sendo incluídos os ausentes do trabalho em decorrência de acidentes. Constata-se, portanto, a necessidade de outros estudos que envolvam os motoboys acidentados que estão impossibilitados de exercer a profissão, seja temporariamente ou definitivamente, para conhecer a real dimensão do problema e as implicações emocionais, familiares e econômicas na vida desses trabalhadores.

\section{Referências}

1. Andrade SM; Jorge MHPM. Características das vítimas por acidentes de transporte terrestre em município da região Sul do Brasil. Rev Saúde Pública. 2000;34(2):149-56.

2. Barros AJD, Amaral RL, Oliveira MSB, Lima SC, Gonçalves EV. Acidentes de trânsito com vítimas: sub-registro, caracterização e letalidade. Cad Saúde Pública. 2003;19(4):979-86.

3. Bastos YGL, Andrade SM, Soares DA. Características dos acidentes de trânsito e das vítimas atendidas em serviço pré-hospitalar em cidade do Sul do Brasil, 1997/2000. Cad Saúde Pública. 2005;21(3):815-22.

4. Soares DFPP, Soares DA. Motociclistas vítimas de acidentes de trânsito em município da região Sul do Brasil. Acta Sci, Health Sci. 2003; 25(1):87-94.

5. Santos AMR, Moura MEB, Nunes BMVT, Leal CF, Teles JBM. Perfil das vítimas de trauma por acidente de moto atendidas em um serviço público de emergência. Cad Saúde Pública. 2008;24(8):1927-38.

6. Gawryszewski VP, Coelho HMM, Scarpelini S, Zan R, Jorge MHPM, Rodrigues EMS. Perfil dos atendimentos a acidentes de transporte terrestre por serviços de emergência em São Paulo, 2005. Rev Saúde Pública. 2009;43(2):275-82.

7. Li Y; Qiu J; LiuD; Zhou JH; Zhang L; Wang ZG; et al. Motorcycle accidents in China. Chin J Traumatol. 2008;11(4):243-6.

8. Mayou R, Bryant B. Consequences of road traffic accidents for different types of road user. Injury. 2003;34(3):197-202.

9. Denatran. Frota de veículos. [internet]. [citado 2 jun 2009]. Disponível em: <http://www.denatran.gov.br/frota.htm>.

10. DATASUS. Mortalidade - Brasil. Óbitos por residência segundo capítulo da CID-10. [internet]. [citado 20 abr 2009]. Disponível em: <http://tabnet.datasus.gov.br/cgi/deftohtm. exe?sim/cnv/obt10uf.def>.

11. Souza ER, Minayo MCS, Malaquias JV. Violência no trânsito: expressão da violência social. In: Ministério da Saúde. Secretaria de Vigilância em Saúde. Impacto da violência na saúde dos brasileiros. Brasília: Ministério da Saúde; 2005. p. 280-301. 
12. Silva DW, Andrade SM, Soares DA, Soares DFPP, Mathias TAF. Perfil do trabalho e acidentes de trânsito entre motociclistas de entregas em dois municípios de médio porte do Estado do Paraná, Brasil. Cad Saúde Pública. 2008;24(11):2643-52.

13. DATASUS. População estimada segundo município. [internet]. [citado 20 nov 2009]. Disponível em: <http://tabnet.datasus. gov.br/cgi/tabcgi.exe?ibge/cnv/poptpr.def>.

14. Dean AG, Dean JA, Coulombier D, Brendel KA, Smith DC, Burten AH, et al. Epi Info, version 6: a word-processing, database, and statistics program for public health on IBMcompatible microcomputers. Atlanta (USA): Centers for Disease Control and Prevention; 1995.

15. Marín-León L, Vizzotto MM. Comportamentos no trânsito: um estudo epidemiológico com estudantes universitários. Cad Saúde Pública. 2003;19(2):515-23.

16. Andrade SM, Soares DA, Braga GP, Moreira JH, Botelho FMN. Comportamentos de risco para acidentes de trânsito: um inquérito entre estudantes de medicina na região sul do Brasil. Rev Assoc Méd Bras. 2003;49(4):439-44.

17. Lin MR, Chang SH, Huang W, Hwang HF, Pai L. Factors associated with severity of motorcycle injuries among young adult riders. Ann Emerg Med. 2003;41(6):783-91.

18. Moraes TD. Fatores de risco de acidentes na atividade dos motoboys: limites das análises quantitativas. Revista de Gestão Integrada em Saúde do Trabalho e Meio Ambiente 2008. [citado 2009 Nov 27]. Available from: http:// www.interfacehs.sp.senac.br/index.php/ITF/article/ viewFile/127/144.

19. Queiroz MS, Oliveira PCP. Acidentes de trânsito: uma análise a partir da perspectiva das vítimas em Campinas. Psicol Soc. 2003;15(2):101-23.

20. Veronese AM, Oliveira DLLC. Os riscos dos acidentes de trânsito na perspectiva dos moto-boys: subsídios para a promoção da saúde. Cad Saúde Pública. 2006;22(12):2717-21.

21. Pinto AO, Witt RR. Gravidade de lesões e características de motociclistas atendidos em um hospital de pronto socorro. Rev Gaúch Enferm. 2008;29(3):408-14.

22. Liberatti CLB. Acidentes de motocicleta em Londrina: estudo das vítimas, dos acidentes e da utilização de capacete. [dissertação]. Londrina: Universidade Estadual de Londrina; 2000.

23. Oliveira NLB, Souza RMC. Diagnóstico de lesões e qualidade de vida de motociclistas, vítimas de acidentes de trânsito. Rev Latino-am Enfermagem. 2003;11(6):749-56.

24. Fitzharris M, Dandona R, Kumar GA, Dandona L. Crash characteristic and patterns of injury among hospitalized motorised two-wheeled vehicle users in urban India. BMC Public Health [serial on the Internet]. 2009 [cited 2009 Nov 27]; 9(11). DOI: 10.1186/1471-2458-9-11. Available from: http://www.biomedcentral.com/content/pdf/14712458-9-11.pdf.

25. Soares, DFPP, Barros, MBA. Fatores associados ao risco de internação por acidentes de trânsito no Município de Maringá-PR. Rev Bras Epidemiol. 2006;9(2):193-205.

26. Andrade SM, Jorge MHPM. Acidentes de transporte terrestre em município da Região Sul do Brasil. Rev Saúde Pública. 2001;35(3):318-20.

27. Veronese AM. Moto-Boys de Porto Alegre: convivendo com os riscos do acidente de trânsito. [dissertação]. Porto Alegre: Universidade Federal do Rio Grande do Sul; 2004.

28. Ladeira RM, Barreto SM. Fatores associados ao uso de serviço de atenção pré-hospitalar por vítimas de acidentes de trânsito. Cad Saúde Pública. 2008;24(2):287-94.

29. Silva DW, Andrade SM, Soares DA, Nunes EFPA, Melchior R. Condições de trabalho e riscos no trânsito urbano na ótica de trabalhadores motociclistas. Physis (Rio J.). 2008;18(2):339-60.

30. Brasil. Presidência da República. Casa Civil. Lei n. 12.009 de 29 de julho de 2009. Regulamenta o exercício das atividades dos profissionais em transporte de passageiros, "mototaxista", em entrega de mercadorias e em serviço comunitário de rua, e "motoboy", com o uso de motocicleta, altera a Lei n. 9.503, de 23 de setembro de 1997, para dispor sobre regras de segurança dos serviços de transporte remunerado de mercadorias em motocicletas e motonetas - moto-frete -, estabelece regras gerais para a regulação deste serviço e dá outras providências [texto na Internet]. Diário Oficial da União; 2009 Jul 30 [citado 2010 Dez 18]. Disponível em: https:// www.planalto.gov.br/ccivil_03/_ato2007-2010/2009/lei/ 112009.htm.

31. Brasil. Conselho Nacional de Trânsito. Resolução n. 356 de 02 de agosto de 2010. Estabelece requisitos mínimos de segurança para o transporte remunerado de passageiros (mototáxi) e de cargas (motofrete) em motocicleta e motoneta, e dá outras providências [texto na Internet]. Diário Oficial da União; 2010 Ago. 04. [citado 2010 Dez 18]. Disponível em: <http://www. denatran.gov.br/download/Resolucoes/RESOLUCAO_ CONTRAN_356_10.pdf $>$.

32. Andrade SM, Soares DA, Matsuo T, Liberatti CLB, Iwakura MLH. Road injury-related mortality in a medium-sized Brazilian city after some preventive interventions. Traffic Inj Prev. 2008;9:450-5.

Recebido em: 27/05/2010

Versão final apresentada em: 28/01/2011 Aprovado em: 28/02/2011 